\title{
Breast Duct
}

National Cancer Institute

\section{Source}

National Cancer Institute. Breast Duct. NCI Thesaurus. Code C93291.

A branched system of tubules that connect the lobules of the mammary gland to the tip of the nipple. 